\title{
European Aspects of the Distribution Network Design. Problems and Models
}

\author{
Bernhard Fleischmann, Universität Augsburg
}

\begin{abstract}
In Germany, the design of distribution networks for consumer goods has focused, in most companies in the last three years, on the extension of the current structure for supplying Eastern Germany. After the gradual changes of the eighties - concentration of the production locations, more frequent supply of smaller quantities, stagnation of rail transports - we were faced with a sudden additional increase of the volume and distances of transportation which has caused a crisis of the road traffic in Germany.
\end{abstract}

On this background, the design of distribution structures for the European market is no longer only a microeconomic problem of single industrial companies. The cost of transportation will be strongly influenced by measurements of the Governments. Logistic service companies of several countries are cooperating in building up European networks, where the distribution for many producers can be bundled. The urgent need for an increasing use of the rail has recently lead to intense planning activities for roadrail terminals, on local, regional and national levels.

We review the various planning problems and the appropriate OR models and report on some experience with planning projects in practice. 